\title{
Criteria for tenure and promotion in doctoral degree programs in psychology: Perceptions of department chairs and heads
}

\author{
ROBERT J. MCCAFFREY, WENDY B. NELLES, and DONN BYRNE \\ The University at Albany, State University of New York, Albany, New York
}

\begin{abstract}
Chairs and heads of $\mathrm{PhD}$-granting programs in psychology were surveyed regarding their perceptions of the minimal criteria for tenure and promotion from assistant to associate professor in their department. The respondents indicated that research was weighted more heavily than either teaching or service activities. The respondents also indicated the minimal number of various activities (e.g., publications) within domains required for tenure and promotion.
\end{abstract}

The concept of academic tenure has been the focus of increased controversy (see Mahoney, 1985). Yet although the debate over the merits of tenure has received considerable attention in the psychological (Mahoney, 1985) and higher education literature (Chait \& Ford, 1982), there has been less discussion about the criteria for tenure and promotion. The criteria traditionally cited are scholarly activities (research), teaching, and service. The relative importance and hence weighting associated with each of these criteria are determined by the characteristics of individual universities and psychology programs.

To date, there have been no published accounts of the criteria necessary for tenure and promotion. The present survey addressed this issue by asking the department chairs and heads of PhD-granting psychology programs to state their perceptions of their minimal departmental criteria necessary for granting tenure and promotion from the rank of assistant to associate professor.

\section{METHOD}

Questionnaires were mailed in July 1987 to the department chairs or heads of the $\mathbf{2 6 5}$ doctoral-degree-granting programs in psychology listed in Graduate study in psychology and associated fields (American Psychological Association, 1986). The department head or chair was requested to provide his or her perceptions of the minimal criteria necessary for tenure and promotion from assistant to associate professor in his or her department. Usable questionnaires were those returned within 12 weeks in self-addressed prepaid envelopes. The questionnaire (presented in the Appendix) was divided into two major sections.

The first section of the questionnaire dealt with the perceived importance of the three major areas typically included as criteria for considering candidates for tenure and promotion: research, teaching, and service. The respondents were requested to indicate the relative percentage of total importance of each of the three major areas. The second section involved an analysis of each of the three major areas. The respondents were requested to indicate the relative percentage of importance within each of the subsections and also to indicate, where appropriate, the number associated with each of the items (e.g., number of articles).

Requests for reprints may be sent to Robert J. McCaffrey, Department of Psychology, The University at Albany, State University of New York, 1400 Washington Avenue, Albany, NY 12222.

\section{RESULTS}

The return rate was $44 \%$ (118 out of 265 ). Therefore, the maximum number of respondents for any item on the questionnaire was 118 . Given the variability of the number of respondents answering particular items, on Tables 1 through 3 the actual number of respondents is indicated following each item. The overall percentage of importance of the three factors in the tenure and promotion process revealed research to be the most important $(M=55.2 \%$; $S D=17.6 ; n=118)$, followed by teaching $(M=31.8 \%$; $S D=12.3 ; n=112)$ and service $(M=13.3 \% ; S D=$ $7.5 ; n=106$ ).

The relative percentage of minimal requirements for tenure and promotion across each of the three major categories is presented in Table 1. Within the category of research, publications in refereed journals were perceived as the most important factor, followed by external funding, with little difference among the remaining three criteria. In the teaching domain, the respondents indicated that student evaluations were the major factor in evaluating a candidate's teaching ability, followed by peer evaluations and the implementation of new courses and/or seminars. Interestingly, there was very little variability among the criteria used to evaluate teaching effectiveness for undergraduate and graduate instruction. The two most important areas within the service category were university-related activities and professional activities related to journals.

In an effort to obtain an estimate of the minimal number of research-related activities required for tenure and promotion, the respondents were asked to indicate the number of activities across several domains within the category of research. The measures of central tendency and the number of respondents indicating a response are presented in Table 2 . Given the variability in the number of responses to each of the categories, the median values were considered more appropriate than the other measures of central tendency. As indicated under the category of 
Table 1

Relative Percentage of Minimal Requirements for Tenure and Promotion within Each of the Three Major Categories

$M \quad S D \quad n$

\section{A. Research}

1. Publications

2. Citations

3. External Funding

4. Conventions

5. Colloquia/Lectures

$61.6 \%$

$8.5 \%$

$19.1 \%$

$10.6 \%$

$6.7 \%$

17.7

9.1

10.3

7.8

4.3

106
69
98
94
82

B. Teaching

\begin{tabular}{lrrr}
\multicolumn{4}{c}{ Undergraduate } \\
1. Student Evaluations & $56.3 \%$ & 26.4 & 91 \\
2. Peer Evaluations & $30.2 \%$ & 20.1 & 76 \\
3. New Courses/Seminars & $16.0 \%$ & 10.5 & 72 \\
& Graduate & & \\
1. Student Evaluations & $55.2 \%$ & 23.8 & 105 \\
2. Peer Evaluations & $29.8 \%$ & 18.0 & 90 \\
3. New Courses/Seminars & $17.4 \%$ & 11.4 & 87
\end{tabular}

C. Service

1. University

$40.6 \%$

20.1

99

2. Community

$14.8 \%$

8.4

82

3. Professional Activities

$\begin{array}{lrrr}\text { (a) Journals } & 32.9 \% & 15.4 & 93 \\ \text { (b) Commissions } & 9.0 \% & 5.5 & 40 \\ \text { (c) Ad Hoc Reviewers } & 12.8 \% & 6.8 & 61\end{array}$

Table 2

Measures of Central Tendency Based on the Minimal Number of Research-Related Activities Required for Tenure and Promotion $M \quad S D$ Median Mode $n$

\begin{tabular}{lccccc}
\hline A. Publications & & & & & \\
1. Refereed Journal Articles & 9.8 & 5.3 & 10.0 & 12.0 & 41 \\
2. Book Chapters & 2.9 & 2.2 & 2.0 & 1.0 & 29 \\
3. Books & 1.8 & 1.6 & 1.0 & 1.0 & 17 \\
4. Book Reviews & 2.9 & 1.8 & 3.0 & 2.0 & 13 \\
5. Published Abstracts & 5.2 & 5.0 & 5.0 & 5.0 & 12 \\
B. Citations & - & - & - & - & - \\
C. External Funding & & & & & \\
1. Federal Grants & 2.7 & 3.5 & 1.0 & 1.0 & 27 \\
2. State Grants & 2.7 & 3.1 & 2.0 & 1.0 & 15 \\
3. Private Foundations & 2.6 & 3.4 & 1.5 & 1.0 & 12 \\
D. Conventions & & & & & \\
1. Symposiums & 3.4 & 2.3 & 3.0 & 3.0 & 21 \\
2. Presentations & 5.1 & 3.2 & 5.0 & 2.0 & 27 \\
$\quad$ Posters/Papers) & & & & & \\
E. Colloquia/Invited Lecture & 3.4 & 1.7 & 4.0 & 5.0 & 19 \\
\hline
\end{tabular}

publications, the median number of articles in refereed journals was 10 , followed by 5 published abstracts, 3 book reviews, 2 book chapters, and 1 edited or authored text. We did not request the respondents to indicate a number of citations as part of the criteria for tenure and promotion. This was based, in part, on the fact that citations are not necessarily positive indications of an individual's work. Moreover, it seemed that it was relatively difficult to arrive at an indication of what an appropriate number of citations would be for a junior faculty member. The reported median number of external funded federal grants was 1.0 , followed by 1.5 for private foundations, and 2.0 for state grants. Under the category of convention presentations, the median number of symposia was 3.0 , and the median number of convention presentations was 5.0. Finally, the category of colloquia and invited lectures revealed a median of 4.0 .

Comparable measures of central tendencies based on the minimal number of service-related activities required for tenure and promotion are presented in Table 3 . The median number of university service-related activities was 2.0 for both department committees and college or university committees. In the area of community service, the median number of consultantships, service to state or local agencies, and volunteer work was 1.0. Under the category of professional activities related to journals, the median was 1.0 for editor, associate editor, and board membership. The median number for ad hoc journal reviews was 4.0. Participation in commissions was evaluated in terms of the relative percentage of importance within the category of service, but no attempt was made to obtain an estimate of the number of these types of activities. Finally, the reported median number of NIH ad hoc reviews was 2.0 with Veterans' Administration Merit Reviews and other types of grant review activity being 1.0 .

\section{DISCUSSION}

The perceived importance of the three major areas typically involved in the consideration of a candidate for tenure and promotion was far from being equally weighted. Rather, research was perceived as accounting for $55 \%$ of the total importance, followed by teaching at $31 \%$, and service-related activities at $13 \%$. In fact, even in the service-related area of professional activities, those associated with research (viz., journal activities) were second only to university-related service.

The most surprising finding of this survey was the number of respondents who indicated that editorship of a journal was a minimal criterion for tenure and promotion. Given that this survey included a number of institutions that have a fixed, non-tenure-track term-appointment policy for assistant professors, this finding is not at all surprising. Specifically, there are departments and entire institutions in which it is incredibly

Table 3

Measures of Central Tendency Based on the Minimal Number of Service-Related Activities Required for Tenure and Promotion

$M S D$ Median Mode $n$

A. University
1. Department Committees
$\begin{array}{lllll}6.1 & 14.0 & 2.0 & 2.0 & 29\end{array}$
2. College/University Committees $\begin{array}{llrrrr}3.1 & 4.9 & 2.0 & 1.0 & 26\end{array}$

B. Community

$\begin{array}{llllll}\text { 1. Consultantships } & 2.0 & 2.3 & 1.0 & 1.0 & 17 \\ \text { 2. State/Local Agencies } & 2.7 & 4.5 & 1.0 & 1.0 & 18 \\ \text { 3. Volunteer Work } & 2.0 & 1.5 & 1.0 & 1.0 & 16\end{array}$

C. Professional Activities

1. Journals
(a) Editor
(b) Associate Editor
(c) Board Member
(d) Ad Hoc Reviewer

2. Commissions

3. Ad Hoc Reviewer

\begin{tabular}{lllllr} 
(a) VA Merit Review & 1.7 & 1.4 & 1.0 & 1.0 & 8 \\
(b) NIH & 3.1 & 3.2 & 2.0 & 1.0 & 13 \\
(c) Other & 2.6 & 2.8 & 1.0 & 1.0 & 11 \\
\hline
\end{tabular}


rare for a faculty member to be tenured and promoted from the rank of assistant professor. More commonly, these programs base their recruitment practices on a "revolving door policy." Thus, only a truly exceptional assistant professor would be considered for tenure and promotion. Under these circumstances, the criterion of journal editor might not be inappropriate.

The available data on the posttenure scholarly activity of academic psychologists (Bridgwater, Walsh, \& Walkenbach, 1982) and other academicians (Ludwig, 1985) indicates that tenure does not result in a decrease in productivity. Ludwig (1985) concludes that tenure does not foster the problem of "deadwood" in academic departments. A proposed solution to the concern that tenure protects unproductive faculty is to exercise great care in the initial appointment process (Smythe, Jones, $\&$ Wilson, 1982). Another solution is to hold down the number of candidates receiving tenure and promotion by setting more stringent criteria. This is in fact the solution reported by $51 \%$ of department chairpersons in a survey by Perri and Zipper (1976) of degree-granting programs in psychology. Certainly such practices can only impact adversely on our growth as a science and potentially on the quality of the educational services provided (Mahoney, 1985). The use of more stringent criteria produces greater pressure on junior faculty to play the "numbers games." Unfortunately, frequency counts of productivity and citation totals do not necessarily reflect the impact or importance of an individual's scholarly contributions (Bridgwater, Walsh, \& Walkenbach, 1982). Nonetheless, the findings of this survey indicate that in general, scholarly productivity is weighted far more heavily than teaching or service. In fact, a survey of Directors of Clinical Psychology Training Programs by Tyler and Clark (1985) revealed that almost one half of the clinic directors felt that quality supervision of students was ignored in tenure and promotion decisions.

The results of the present survey reflect the minimal criteria for tenure and promotion in $\mathrm{PhD}$-granting programs in psychology. In addition, the data are based on the department chairs' and heads' percep- tions of the minimal criteria and not the actual minimal criteria in their respective departments. As such, the results of the present survey should not be misinterpreted as necessarily reflecting the actual criteria used for tenure and promotion in $\mathrm{PhD}$-granting programs in psychology.

Finally, the present survey represents a first step in the evaluation of a complex decision-making process involving multiple levels of evaluators. In this regard, the present survey was designed to focus on objective criteria from a macroanalytic level. The evaluation of subjective factors and the complex interactions between objective and subjective criteria require a microanalysis based on existing data.

\section{REFERENCES}

American Psychological Association. (1986). Graduate study in psychology and associated fields. Washington, DC: Author.

Bridgwater, C. A., Walsh, J. A., \& Walkenbach, J. (1982). Pretenure and posttenure productivity trends of academic psychologists. American Psychologist, 37, 236-238.

Chait, R. P., \& Ford, A. T. (1982). Beyond traditional tenure. San Francisco: Jossey-Bass.

Ludwig, A. M. (1985). Is there life after tenure? American Journal of Psychotherapy, 39, 49-56.

MAHONEY, M. J. (1985). Open exchange and epistemic progress. American Psychologist, 40, 29-39.

Perri, M. G., \& ZIPPER, M. M. (1976). Are psychology departments dealing with the tenuring-in problem? A survey of department chairpersons. Psychological Reports, 39, 1321-1322.

Smythe, C. McC., Jones, A. B., \& Wilson, M. P. (1982). Tenure in medical schools in the 1980's. Journal of Medical Education, 57, 349-360.

Tyler, J. D., \& Clark, J. A. (1985). Promoting clinical expertise in academic faculty supervisors. Professional Psychology: Research \& Practice, 16, 902-904.

\section{APPENDIX \\ Tenure and Promotion Questionnaire}

I. Three Major Areas
A. Research
B. Teaching
C. Service (University/College; Community; Professional)

II. Specifics

A. Research

1. Publications

$\mathrm{n}=$ _ Articles in refereed journals

$\mathrm{n}=\ldots$ Book chapters

$\mathrm{n}=$ Books

$\mathrm{n}=$ _- Book reviews, proceedings

$\mathrm{n}=\ldots$ Published abstracts

2. Citations

3. Funding-External
$\mathrm{n}=$
Federal grants
$\mathrm{n}=$ _ State grants
$\mathrm{n}=\ldots$ Private foundations

Percentage of importance

Total

$100 \%$

Percentage of importance within each category 

4. Conventions
$\mathrm{n}=\_$Symposium
$\mathrm{n}=\ldots$ Presentations (Papers/Posters)
5. Colloquia/Invited Lectures $\mathrm{n}=$

B. Teaching

1. Student Evaluations

2. Peer Evaluations

3. Development of New Courses/Seminars

Total

Total

$100 \%$

(Undergraduate)

(Graduate)
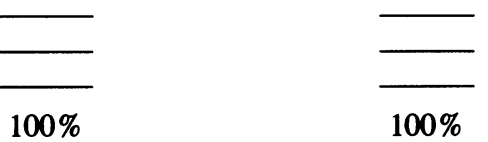

C. Service

1. University

$\mathrm{n}=$ a. Dept. Committees

$\mathrm{n}=$

b. College/University-Wide

Committees (e.g., IRB)

2. Community
$\mathrm{n}=$
a. Consultantships
$\mathrm{n}=$
b. State/Local Agencies
$n=$
c. Volunteer Work

3. Professional Activities
a. Journals
$\mathrm{n}=$
1. Editor
$\mathrm{n}=$
2. Associate Editorship
$\mathrm{n}=$ 3. Board Membership
$n=\ldots$ 4. Ad Hoc Review
b. Commissions
c. Ad Hoc Reviewer
$\mathrm{n}=$
1. VA
$\mathrm{n}=-2$. NIH
$\mathrm{n}=$ 3. etc. 